\title{
Nevo de células fusiformes de Reed na conjuntiva
}

\section{Spindle cell nevus of Reed in the conjunctiva}

Juliana de Lucena Martins Ferreira', Márjorie Sabino Façanha Barreto Rolim², José Luciano Leitão de Alencar³, Fernando Queiroz Monte ${ }^{4}$

\section{Resumo}

Os autores relatam um caso de nevo de Reed, lesão que apresenta aspecto histológico de malignidade, mas tem evolução benigna. Paciente de 48 anos, masculino, cor parda, apresentava pterígio nasal no olho direito, associado a uma lesão pequena e pouco pigmentada localizada na cabeça do mesmo. Realizou-se exérese de ambos, sem intercorrências, sem sinais de recidiva. $\mathrm{O}$ exame histopatológico revelou lesão com bordas definidas, restrita ao epitélio, constituída por células fusiformes perpendiculares à superfície, com pigmentação melânica esparsa. O diagnóstico inicial foi nevo de Spitz, mas, posteriormente, chegou-se à conclusão que se tratava do nevo de células fusiformes de Reed. O presente relato é o segundo na literatura mundial e o primeiro no Brasil.

Descritores: Nevo fusocelular; Nevo de células epitelióides e fusiformes; Melanoma; Neoplasias da conjuntiva; Relatos de casos

\section{AbStRACT}

The authors report one case of nevus of Reed, which has histological aspect of malignancy, but a benign evolution. A 48-years-old brown skin male presented nasal pterygium in right eye, associated with a small and poorly pigmented lesion located on the pterygium head. Both were excised without complications and, currently, there is no recidivation. The histopathological examination revealed one lesion with defined edges, limited to the epithelium, consisted of spindle cells perpendiculars to the surface and with sparse melanin pigmentation. The initial diagnosis was Spitz nevus, but, afterwards, we concluded that was the spindle cell nevus of Reed. This report is the second in the international literature and the first in Brazil.

Keywords: Nevus, spindle cell; Nevus, epithelioid and spindle cell; Melanoma; Conjunctival neoplasms; Case reports

\footnotetext{
${ }^{1}$ Pós-graduanda (Doutorado) pela Faculdade de Medicina de Ribeirão Preto da Universidade de São Paulo (USP) - Ribeirão Preto (SP), Brasil; Médica Oftalmologista do Centro Avançado de Retina e Catarata - Fortaleza (CE), Brasil;

${ }^{2}$ Oftalmoclínica - Fortaleza (CE), Brasil;

${ }^{3}$ Oftalmed - Fortaleza (CE), Brasil;

${ }^{4}$ Hospital Geral de Fortaleza (HGF) - Fortaleza (CE), Brasil; Patologista do Laboratório Biopse - Fortaleza (CE), Brasil;
}

Trabalho realizado no Laboratório Biopse - Fortaleza (CE) - Brasil.

Interest conflict - None

Recebido para publicação em 20/10/2010 - Aceito para publicação em 27/4/2011 


\section{INTRODUÇÃO}

A s lesões pigmentares da conjuntiva são um desafio para o diagnóstico e tratamento. Enquanto a maioria dos estudos direciona-se ao melanoma conjuntival, é também importante reconhecer variantes de nevo incomuns e benignos, que podem simular o melanoma, tais como: nevo de Spitz (ou nevo de células fusiformes e epitelióides, impropriamente denominado de melanoma juvenil) e nevo de Reed (ou nevo de células fusiformes) ${ }^{(1,2)}$.

O nevo de células fusiformes de Reed é uma lesão melanocítica benigna, distinta em suas características clínicas e histopatológicas. Foi primeiramente descrito na pele por Reed et al., em $1975^{(3)}$, e, na conjuntiva, por Seregard, no ano 2000 (2), embora Folberg et al., em $1989^{(4)}$, tenham postulado a possibilidade de sua existência no limbo. Atualmente, não há relatos desta lesão conjuntival na literatura brasileira.

O objetivo deste relato foi ilustrar as características do nevo de Reed na conjuntiva, ressaltando a importância de um diagnóstico diferencial acurado dessas lesões, evitando, assim, cirurgias radicais desnecessárias.

\section{Relato do caso}

Paciente de 48 anos, masculino, cor parda, dentista, natural e procedente de Fortaleza (CE), procurou o serviço de oftalmologia da clínica Oftalmed em 2005, com pterígio no olho direito há, aproximadamente, quatro anos, que ultimamente incomodava e com intenção de remover a lesão. Negava antecedentes de outras doenças oculares, bem como história familiar. A biomicroscopia do olho direito revelava pterígio nasal ultrapassando o limbo em $1 \mathrm{~mm}$ e com $5 \mathrm{~mm}$ da largura. Na cabeça do pterígio, entre 2 e 3 horas, foi observada uma lesão de superfície lisa, plana, contendo pontos enegrecidos esparsos, com pequenos vasos contornando-a. O paciente informou nunca ter percebido esta lesão. Não havia outras alterações ao exame ocular.

Optou-se pela exérese da lesão em conjunto com o pterígio, sendo realizada ceratectomia superficial. Em seguida, foi colocado enxerto conjuntivo-limbar livre removido da região bulbar temporal-superior e sutura com mononylon 10-0 em pontos separados e não sepultados. A cirurgia transcorreu sem intercorrências e, com aproximadamente quatro anos de observação, não há sinais de recidiva.

O material removido foi fixado em formol neutro, a $10 \%$, e encaminhado para o Laboratório Biopse, onde se executou inclusão em parafina, cortes histológicos de
$5 \mu$ e coloração pela hematoxilina-eosina (HE).

O exame macroscópico revelou elipse de mucosa com superfície compacta e parda medindo $7 \times 5 \times 2 \mathrm{~mm}$.

A microscopia evidenciou:

1.Epitélio do tipo estratificado cúbico, que se tornava, em alguns locais, pavimentoso e com leve ceratinização. Presença de acantose moderada com leve perda da polaridade em uma área limitada que circundava a massa tumoral (Figura 1);

2.Massa tumoral restrita ao epitélio e constituída por células fusiformes, predominantemente perpendiculares à superfície e com pigmentação melânica esparsa (Figura 2). As bordas da tumoração eram bem definidas;

3.O tecido conjuntivo apresentava massas elastóticas, algumas com hialinização, onde, normalmente, deveria existir somente tecido conjuntivo frouxo. Sob a tumoração descrita, havia tecido conjuntivo denso avascular, porém apresentava áreas muito vascularizadas em tecido conjuntivo frouxo, no qual existiam também células inflamatórias.

O diagnóstico histopatológico inicial foi de tumor limbar com pigmentação, constituído por células fusiformes (conforme descrito no item 2 da microscopia), equivalente, no adulto, ao nevo de Spitz da infância, sobre o pterígio (de acordo com as massas elastóticas e a hialinização descritas no item 3 da microscopia). Esta lesão, rara, tendo despertado dúvidas ao patologista, levou-o a uma consulta à literatura relacionada à patologia geral, chegando à conclusão que se tratava de um nevo de Reed da conjuntiva.

\section{Dıscussão}

As lesões melanocíticas da conjuntiva podem causar ansiedade ao oftalmologista, pois a taxa de mortalidade nos pacientes com melanoma conjuntival é próxima de $25 \%$. Os nevos conjuntivais não diferem dos nevos cutâneos, devendo ser considerados como verdadeiras neoplasias benignas, derivadas da crista neural. O diagnóstico definitivo é histopatológico e o tratamento é a biópsia excisional ${ }^{(6,7)}$.

Apesar de serem considerados tumores congênitos, nem sempre estão presentes ao nascimento, podendo ocorrer alterações na lesão ao longo da vida. Este é um dos motivos que dificulta a determinação da idade em que surgiu. $\mathrm{O}$ paciente geralmente procura o médico quando percebe aumento de tamanho, mudança na coloração, novas lesões pigmentares ao redor, prurido ou outras lesões associadas ${ }^{(8,9)}$, como o pterígio, o que ocorreu no caso aqui apresentado. 


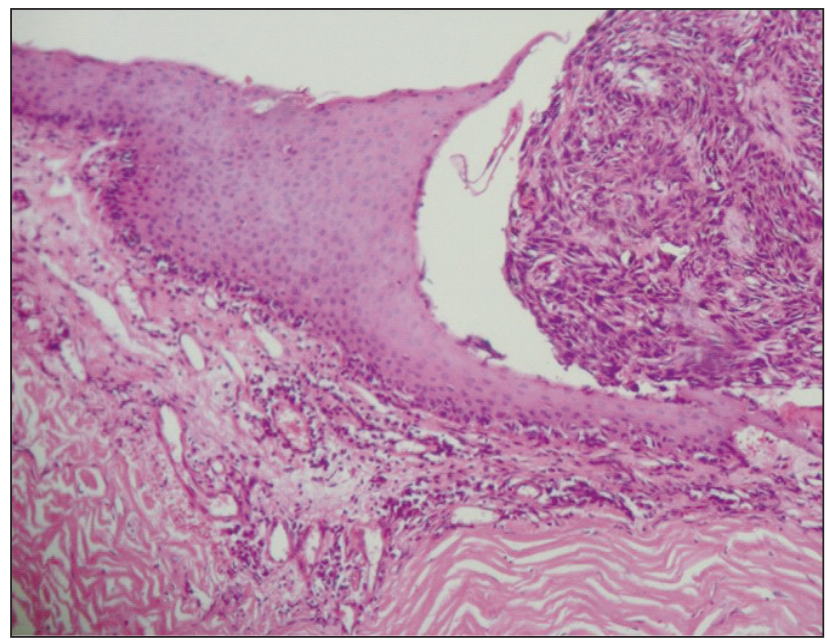

Figura 1: Massa tumoral à direita; o epitélio da vizinhança apresenta acantose significativa e existe um descolamento, por artefato, entre o epitélio e a massa, mostrando a nítida separação entre eles (parafina, HE, x40)

A localização do nevo segue a distribuição dos pigmentos melânicos na conjuntiva, presente na conjuntiva perilímbica, carúncula e na transição pelemucosa da margem palpebral. Estudo anterior mostrou que o acometimento mais freqüente ocorre no limbo temporal $(45,4 \%)$, seguido pelo nasal $(32,7 \%)^{(8)}$, como o presente neste relato.

Surgem dificuldades no diagnóstico clínico e histopatológico quando nos deparamos com variedades incomuns de tumores melanocíticos, de comportamento biológico benigno e aspecto histológico maligno, além dos tumores propriamente malignos ${ }^{(5,10)}$. Dentre esses, selecionamos três que estão relacionados com o presente caso: o nevo de Spitz, lembrado no diagnóstico histopatológico inicial; o nevo de Reed, a conclusão diagnóstica e o melanoma conjuntival maligno, um importante diagnóstico diferencial. Existem muitas razões para o erro diagnóstico, pautado pela falta de conhecimento ou experiência com essas raras lesões ${ }^{(5)}$.

O nevo de Spitz, talvez o diagnóstico diferencial mais difícil com o melanoma, é o exemplo clássico da lesão melanocítica de comportamento benigno e que pode ter intensas atipias celulares, além de mitoses. Porém, há simetria citológica entre estas células, enquanto as células do melanoma apresentam pleomorfismo mais acentuado. As células maduras da base da lesão permeiam as fibras do tecido conectivo, formando filas indianas, o que difere do padrão fascicular de invasão do melanoma. ${ }^{(11)}$

No ano de 1975, o grupo de Reed descreveu lesões que foram nomeadas de nevo de células fusiformes, ressaltando que lesões similares, descritas anteriormente, não tinham recebido reconhecimento clínico e patológico.

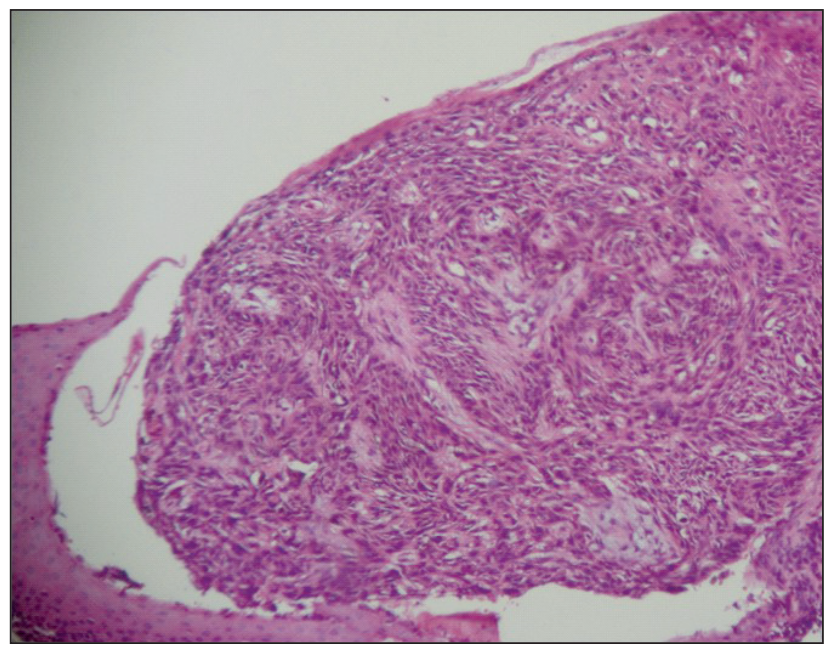

Figura 2: Massa tumoral constituída de células fusiformes predominantemente perpendiculares à superfície e com reduzida pigmentação (parafina, HE, x40).

Desde então, referências à mesma na literatura têm sido escassas, permitindo a subestimação e erros diagnósticos desta tumoração. Alguns autores interpretam o nevo de células fusiformes, mais descrito em mulheres, na terceira década de vida, como uma variante do nevo de Spitz, mais comumente encontrado em crianças. Enquanto outros acreditam que há diferenças suficientes para fazer a distinção entre essas entidades. Clinicamente, a maioria dos nevos de Reed é descrita como muito pigmentados e os de Spitz como não pigmentados ${ }^{(2,3,5,12)}$. No presente relato, a lesão era pouco pigmentada, o que contribuiu para o primeiro diagnóstico, de nevo de Spitz. No entanto, a tumoração não estava presente desde a infância.

No ano 2000, Seregard descreveu o primeiro, e até agora único, relato na literatura de nevo de Reed na conjuntiva. Lesão superficial, simétrica e bem circunscrita, constituída de células fusiformes sem atipias, orientadas perpendicularmente ao epitélio, sem figuras de mitose, podendo apresentar poucos glóbulos eosinofílicos (Kamino bodies), mais característicos do nevo de Spitz, os quais não foram encontrados no paciente aqui relatado, apesar de estar presente em $80 \%$ dos nevos de células fusiformes da pele e raramente encontrados nos melanomas ${ }^{(2,5)}$.

A histopatologia mostra o nevo de Spitz composto, predominantemente, de células epitelióides, enquanto o de Reed, com células fusiformes. Ambas são simétricas, com uma marcante tendência das células orientadas verticalmente, descritos como "riscos de chuva". O padrão de crescimento da maioria dos nevos de Reed é expansivo e "empurrando", em contraste com o padrão infiltrativo, visto nos nevos de Spitz típicos. Mas, alguns nevos de células fusiformes podem apresentar células 
epitelióides, sugerindo uma superposição com o nevo de Spitz, além de atipias, causando confusão diagnóstica também com o melanoma ${ }^{(2,5,13)}$. De acordo com o tipo preponderante de células, a ausência de atipia e o padrão de crescimento evidenciados neste paciente, firmouse o diagnóstico de nevo de Reed.

Pode-se encontrar infiltrado inflamatório variável e vasodilatação local, assim como nos demais nevos, sendo os linfócitos e os plasmócitos os elementos mais frequentes ${ }^{(910,11)}$. O paciente também apresentava elastose e hialinização no tecido conjuntivo, correspondendo às alterações histopatológicas encontradas, caracteristicamente, no pterígio.

Recentes pesquisas afirmam que o prognóstico após completa retirada do nevo de Reed é excelente, com ausência de recorrência local ou à distância ${ }^{(2,5)}$. Após quatro anos de seguimento, o paciente em questão não demonstrou sinais de recorrência ou metástase.

O nevo de células fusiformes de Reed é uma entidade clínico-patológica distinta, que merece mais reconhecimento e pesquisas para determinar sua prevalência, comportamento biológico e se pode ser significativamente associado à outra lesão melanocítica benigna ou maligna. É provável que esse tumor ocorra mais freqüentemente na conjuntiva do que a literatura sugere, ${ }^{(1,5)}$ tendo em vista que muitas vezes as lesões removidas não são avaliadas, ressaltando a importância do exame anatomopatológico de peças e fragmentos cirúrgicos. Este é o primeiro relato deste tipo de lesão na literatura nacional e o segundo na literatura mundial, contudo a primeira descrição do achado desta lesão em associação com pterígio.

\section{REFERÊNCIAS}

1. Jakobiec FA, Zuckerman BD, Berlin AJ, Odell P, MacRae DW, Tuthill RJ. Unusual melanocytic nevi of the conjunctiva. Am J Ophthalmol. 1985;100(1):100-13.

2. Seregard S. Pigmented spindle cell naevus of Reed presenting in the conjunctiva. Acta Ophthalmol Scand. 2000;78(1):104-6.

3. Reed RJ, Ichinose H, Clark WH Jr, Mihm MC Jr. Common and uncommon melanocytic nevi and borderline melanomas. Semin Oncol. 1975;2(2):119-47.

4. Folberg R, Jakobiec FA, Bernardino VB, Iwamoto T. Benign conjunctival melanocytic lesions. Clinicopathologic features. Ophthalmology. 1989; 96(4): 436-61.

5. Smith NP. The pigmented spindle cell tumor of Reed: an underdiagnosed lesion. Semin Diagn Pathol. 1987;4(1):75-87.

6. Cursino JW, Santo RM, Cursino SRT. Patologia ocular. Rio de Janeiro: Cultura Médica: CBO; 2002. p. 47-9.

7. González Almaraz G, Pineda Cárdenas MAA. El sistema APUD en la oftalmología: II. Tumores de la cresta neural. Derivados del sistema pigmentario (melanogénico): nevi y melanomas palpebrales y conjuntivales. Rev Mex Oftalmol. 1999;73(5):205-19.
8. Schellini SA, Silva MRBM, Marques MEA, Padovani CR. Nevo conjuntival. Avaliação clínica e histopatológica. Rev Bras Oftalmol. 1997;56(11):853-7.

9. Gittinger JW Jr, Smith TW. Cutaneous melanoma-associated paraneoplastic retinopathy: histopathologic observations. Am J Ophthalmol. 1999;127(5):612-4.

10. Cordero Moreno R, Pifano I. Lesiones pigmentadas benignas de la conjuntiva: conducta clínica. Rev Oftalmol Venez. 1986;44(1):33-43.

11. Veronese LA, Marques MEA. Critérios anatomopatológicos para melanoma maligno cutâneo: análise qualitativa de sua eficácia e revisão da literatura. J Bras Patol Med Lab. 2004;40(2):99-112.

12. Kolde G, Vakilzadeh F. Der pigmentierte Spindelzellentumor. Hautarzt. 1987;38(12):743-5.

13. Cursino JW. Lesões pigmentadas da conjuntiva bulbar. An Oftalmol. 1984;3(1):124-6.

Endereço para correspondência: Juliana de Lucena Martins Ferreira. Av. Dom Luis, 1233 - $14^{\circ}$ andar Aldeota CEP 60160-230 - Fortaleza (CE) Tel: (85) 34866366 E-mail: julianalmf@yahoo.com.br 